\title{
MAINTENANCE AS A TOOL FOR INCREASING THE EFFICIENCY OF CHEMICAL- TECHNOLOGICAL PROCESS
}

\author{
Lenka Branska ${ }^{1}$, Zuzana Pecinova ${ }^{2}$, Michal Patak ${ }^{3}$ \\ ${ }^{3}$ Department of Economy and Management of Chemical and Food Industries, Faculty of Chemical Technology, \\ University of Pardubice, Studentska 95, 53210 Pardubice, Czech Republic \\ E-mails: 'lenka.branska@upce.cz (corresponding author); ${ }^{2}$ zuzana.pecinova@upce.cz; ${ }^{3}$ michal.patak@upce.cz
}

\begin{abstract}
Reliability, flexibility and speed belong among particularly valued parameters of contractor. In manufacturing companies, the achievement thereof is significantly limited by the reliability of production equipment. The aim of the article is to analyze an applied production equipment maintenance system with heavily utilized production equipment, and to define guidelines for its improvement. A content analysis of information obtained in a primary qualitative research and a comparison with theoretical approaches made it possible to define an adequate combination of various types of maintenance, including methods and tools that are not primarily intended for the examined type of manufacturing processes.
\end{abstract}

Keywords: maintenance; maintenance system; production equipment; manufacturing; chemical industry.

JEL Classification: M21; M11.

\section{Introduction}

The current market environment is characterized by continouos introduction of new products, difficulty of predicting changes in demand, shortening product life cycles and reducing profit margins (Chan, Prakash 2012). In such an environment, only those companies are successful that consistently strive for customer satisfaction through creation special and unique value for a customer (Jelinkova, Munzarova 2007). Increasing satisfaction through better products or services is accepted as an essential step leading to customers' repurchase intentions and/or reducing switching intensions (Park, Jang 2014). Customer satisfaction is often directly dependent on the reliability, flexibility and speed of suppliers.

This forces suppliers to implement advanced manufacturing technologies and just-intime production systems, which allow them to manufacture products massively in a customized and highly efficient way (Marquez, Gupta 2006). The competitiveness and performance of manufacturing companies depend on the availability, reliability and productivity of their production equipment (Van Horenbeek, Pintelon 2014). This, however, increases requirements for the maintenance of production equipment because the disruption to production flows can quickly become costly by rapidly disrupting a large portion of the operation (Marquez, Gupta 2006). The maintenance process enhances customer satisfaction and reliability of the products, and increases the profit of the manufacturer (Chan, Prakash 2012).

In recent decades, perception of maintenance has changed significantly - a "necessary evil" becomes an important "adding value" activity (Van Horenbeek, Pintelon 2014). Therefore, the so called maintenance management is currently coming to the fore, being one of rapidly evolving fields of business management, and its importance throughout the years has grown (Dekker 1996). It is a set of tools, technologies and methods that are used to implement the process of maintenance and the improvement thereof.

Maintenance system of individual production equipment must respect the specificities of the production process and production equipment used therein. According to a study conducted in the chemical industry, accidents associated with maintaining have a significant impact on occupational safety. About $40 \%$ of serious accidents in the industry are related to maintenance, $80 \%$ of those occurring during the maintenance phase itself and $20 \%$ in normal operations as a result of deficiencies in maintenance management (Hale et al. 1998).

Within maintenance management, it is important to perform prioritization and always primarily focus on bottlenecks, i.e. extremely busy production facility, where failure will cause major problems. Implementation of an efficient maintenance policy can increase company production 
capacity without investing in new machinery while ensuring availability, quality rate and growth of performance (Al-Najjar, Alsyouf 2004; Maletic et al. 2015). As soon as the problems are identified, it is necessary to solve them. At the same time, the principal roles are played by the employees (Vlckova 2012).

For the aforementioned reasons, in our research we focused on the management of maintenance in an extremely busy production facility, where a chemical-technological process takes place, in order to identify possible directions to improve a realistically applied system of maintenance. This paper aims to:

- Define a recommended content of the strategic and tactical-operative management of maintenance of the production equipment as a theoretical framework for analyzing the maintenance system in the selected manufacturing process.

- Map a realistically used production equipment maintenance system used in more than 95 percent, whose failure rate reduces the ability of the company to successfully serve customers.

- Based on the identification of weaknesses of the applied maintenance system, suggest guidelines for improvement.

To achieve the objectives defined, we used methods of scientific work, especially scientific literature search, content analysis of information obtained in a primary qualitative research and comparison of results from the analysis of theoretical approaches to the maintenance of production equipment.

The theoretical contribution of the paper is developed knowledge about the management of maintenance of production equipment used in chemical-technological production processes and knowledge about the possibilities of combining various methods used in the maintenance of production equipment. The paper has also its importance for corporate practice, not just for managers of chemical-technological processes. It may be a useful suggestion for improving realistically applied systems of maintenance.

\section{Previous research}

Theoretical approaches to maintenance management are developed mainly in two basic ways. Mathematical modelling (for example Dekker 1996; Martorell et al. 1999; Hijes, Cartagena 2006; Chan, Prakash 2012; Muchiri et al. 2014) is used to improve the maintenance system, while the sec- ond direction is the creation and implementation of new approaches such as TPM or RCM (for example Lycke 2003; Chompuinwai et. al. 2008; Branska, Silhava 2010; Bakri et al. 2012.).

Maintenance is a business function that serves and supports the primary process in an organization (Chan, Prakash 2012). In a complex way maintenance is defined as "a combination of all technical and associated administrative activities required to keep equipments, installations and other physical assets in the desired operating condition or restore them to this condition" (BSI 1984). It is a recovery process, which is intended to systematically remove the effects of physical (and partially also economical) degradation of various elements of the entire system of the equipment which occurs as a result of its use (but also due to aging, for example) in the manufacturing process (Makovec 1998). This process needs to be effectively managed. The aim is to ensure the correct operation of equipments and to obtain the greatest availability as possible (Hijes, Cartagena 2006).

In terms of maintenance, many businesses encounter a range of problems, which include, for example, inaccurate information about the actual operation of production equipment, improper timing of technical inspections and preventative maintenance, use of inappropriate procedures for maintenance, poor record-keeping and spare parts inventory planning, inadequate use of human potential and many others (Cervenka 2001). Therefore, maintenance in enterprises often requires partial or complex improvement.

Both practitioners and management scientists agree on the importance of planning the maintenance of production equipment in manufacturing companies (Rustogi, Strusevich 2012). Research in more than 500 manufacturing companies from various industrial sectors carried out by A. T. Kearney Consulting showed that unplanned or ill-planned maintenance or repairs are approximately three times more expensive than if the same actions were carefully planned. This leads to the conclusion that, in an extreme case, 66 percent of the cost spent for the poorly planned repairs could be saved (Cervenka 2001).

Creating or updating the maintenance schedule must therefore begin with an inventory of all devices and equipment, including their properties and functional relations. Other important inputs include records of failures, economic information (acquisition costs, direct and indirect maintenance costs), needs and operational factors, also the type of maintenance to be carried out and any legal or contractual obligations concerning maintenance. 
At the same time, it is necessary to find out what resources are available for maintenance, both means (tools, auxiliary equipment, etc.) and human resources and their qualifications, and which maintenance tasks can or must be contracted out (Hijes, Cartagena 2006).

After the analysis is made, the next thing to do in planning machine maintenance is to define the objectives, decide on appropriate maintenance strategy and method of measuring its performance. On the basis thereof, tactical and operational management of maintenance is implemented (see Figure 1).

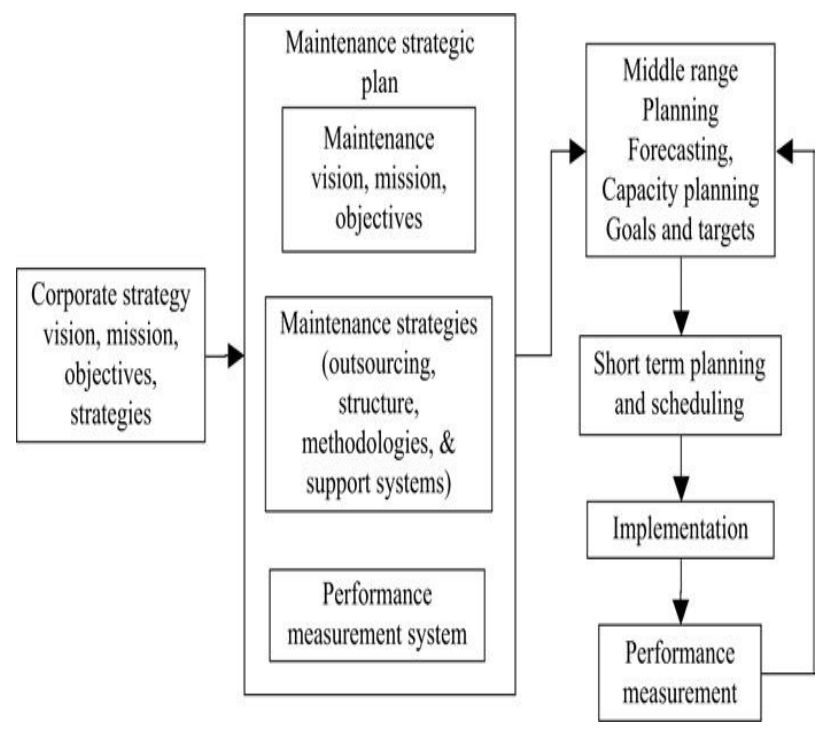

Fig. 1. Maintenance management process (Source: Al-Turki 2011)

The selection of an appropriate maintenance strategy for a manufacturing system is a difficult task (Chan, Prakash 2012), but it is a necessary condition for the success of maintenance and ensures the effectiveness of subsequent implementation plans for maintenance, inspection and improvement (Murthy et al. 2002). Appropriate maintenance policy will improve the efficiency of a manufacturing plant, as it will produce higherquality products and will provide better economy or more profitability (Chan, Prakash 2012).

Maintenance strategy addresses the conceptual issues associated with maintenance of production equipment, especially with (Al-Turki 2011):

- Maintenance system.

- Outsourcing and organization of maintenance within own enterprise.

- Ensuring human resources for maintenance of production equipment.

- Planning of material resources and spare parts and planning of technical resources.
Maintenance of the system can be performed either preventively before or correctively after its failure or failure of one of its components (Aghezzaf 2016). The basic maintenance systems include Failure-Based Maintenance, Preventive Maintenance (Time - based maintenance), ConditionBased Maintenance, Total Productive Maintenance, and Total Quality Maintenance (Chan, Prakash 2012) and RCM.

When using Failure-based maintenance (FBM), maintenance is done only when the equipment fails. Using Time-based (or Use-based) maintenance (TBM) means that maintenance is carried out at specified time intervals. Conditionbased maintenance $(\mathrm{CBM})$ is a system, when preventive maintenance is carried out whenever a given system parameter or condition reaches a predetermined value. The condition of the equipment is measured at predetermined intervals to determine when the component will fail (Muchiri et al. 2014). Total Productive Maintenance (TPM) is a maintenance improvement program concept and philosophy that resembles total quality management (Peters 2001). Many of the same principles and concepts, such as employee involvement, documentation, teamwork, leadership, performance measurement, etc., are applied in TPM (Chompuinwai et al. 2008).

Total Quality Maintenance can be defined as a maintenance policy that emphasises more on the intensive use of the real-time data acquisition and continuous analysis to detect causes of failure, and to change the machine condition according to the data to control damage at a very early stage so as to provide a quality product to a customer at the right time (Chan, Prakash 2012).

Reliability Centred Maintenance is an important approach which was initially oriented towards airplane maintenance. It directs maintenance efforts at those parts and units where reliability is critical (Dekker 1996).

Different maintenance systems lead to different equipment performance (Muchiri et al. 2014). Maintenance of any form has significant effect on production output rate. However, the type of maintenance applied is important and should be carefully studied before implementation (Savsar 2006). For example, the success of the CBM policy is highly dependent on the deterioration duration. With minimal deterioration duration, CBM is not effective and thus other policies may provide better equipment performance (Muchiri et al. 2014).

The worst policy is the corrective maintenance policy case, which is operate-to-failure and then repairs case (Savsar 2006). 
Maintenance activities play an increasingly central role in the trade-off between the conflicting objectives of the economic service, efficient productivity and safe operation, which drive the industrial world (Muchiri et al. 2014). More preventive maintenance may limit the number of failures (uptime increase), but machines are unavailable during this maintenance time (uptime decrease). Managing the overhaul interval is also critical for manpower requirements: more frequent maintenance visits cause a need for more field technicians who perform the service of machine overhauls, but for less field technicians who perform the repair of machine failures (Lieckens et al. 2015). Zhang et al. (2013) studied multi-component systems, which environmental conditions and opportunistic maintenance involve. Through numerical examples, they demonstrate that environmental conditions and opportunistic maintenance pose significant impacts on how to determine an optimal maintenance policy, and that how cost parameters affect the optimal average costs and maintenance policies.

There are several methods proposed for deciding which level of maintenance should be applied to the equipment and how the maintenance resources have to be distributed. Whitaker and Samaniego (1989) proposed a method based on an evaluation of reliability. Martorell et al. (1996) and Martorell et al. (1999) suggested that preventive maintenance activities should depend on the age of the components and proposed age-dependent models for evaluating the risks and costs of maintenance; while Chelbi and Ait-Kadi (1999) analyzed some inspection strategies for randomly failing equipment. Hijes and Catagena (2006) described the multi-criterion classification of critical equipments provides a percentage value for all equipment, called the criticality index, as a representative of its criticality. This index is calculated as a pondered function of multiple factors, each of which constitutes a different criterion for analysing the importance that all equipment has for the company. The criticality index allows equipment to be classified according to its importance for the company and constitutes, therefore, a basic reference value that, together with other economic, technical and strategic factors, helps to decide which level of maintenance should be applied to the equipment and how the maintenance resources must be distributed. Tan et al. (2011) proposed the analytical hierarchy process technique that combines many features which are important for the maintenance policy: safety, cost, value added and feasibility. The results of their survey confirmed how the ana- lytical hierarchy process can enhance and improve the understanding of the dynamic of similar complex problem and represents an effective approach to arrive at decision.

Based on the outcomes of strategic planning, tactical plans are made, which specify and elaborate strategic plans, specify substantive tasks and budgets. Tactical and operational planning of maintenance is very difficult. This is primarily because the number of repairs is large, their scope is different and they are implemented with minor or major irregularities.

The tactical planning is followed by operational planning, which is used to secure the routine course of activities, solving problems, failures and shortcomings. The maintenance plan determines the set of operations, time intervals, and resources (staff, supplies, and spare parts) necessary to conduct maintenance operations (Duffuaa 2000; López-Santana et al. 2016). The decision-maker determines how many maintenance periods to allocate and when to start each of them in order to minimize the makespan, i.e., the completion time of the last job to be processed (Rustogi, Strusevich 2012).

Maintenance programs range from the very simple to the quite sophisticated ones. Perhaps, the simplest plan is to adopt a rigid maintenance schedule where predefined activities are carried out at fixed time intervals (Khalaf et al. 2015).

After realization, performance plans are reviewed in a suitable manner, which is feedback. Feedback is intended both to provide information on maintenance activities and to provide a basis suitable for modification of the schedules in the next period, so there was continuous improvement and streamlining of the overall maintenance system (Solilova 2015).

Moreover, the link with the manufacturing and corporate strategy should be established in order to establish an maintenance performance measurement system useable throughout the entire company. In this way, maintenance performance measurement should be defined on all management levels (i.e. strategic, tactical and operational) (Van Horenbeek, Pintelon 2014).

It is also important to realize that maintenance schedules are used not only to manage the activity itself, but they are also part of other plans (production plan, technical development plan, human resource plan, supply, costs etc.), and therefore they must be harmonized with these plans and approved (Ziegler 1993). In practice, however, plans for production and maintenance are often made independently. Maintenance is planned and implement- 
ed on the basis of system reliability data, and neither the forecasted production orders nor planned product mix is taken into account. Production planning is then carried out within the limits imposed by the system's maintenance schedule. The result thereof is in that the production schedules and maintenance schedules are not optimal with regard to the overall objective of minimizing the combined production and maintenance related costs (Aghezzaf et al. 2016).

\section{Methodology}

The primary qualitative research took place in a chemical industry enterprise, in a plant with chemical-technological production process. In terms of capacity, the production equipment in the plant is utilized to at least 95 percent.

Primary data was gathered in 2015, based on interviews conducted with the main maintenance mechanic of the company and then with professional technical personnel of production and maintenance. Another source of information was a corporate documentation. Interviews were conducted so as to obtain all the information contained in the interview guide. Subsequently, we conducted a content analysis of the collected information and comparison with theoretical approaches to the maintenance of production equipment. This allowed us to fulfil the main objective of the research work, i.e. to propose guidelines for improving the applied system of maintenance of the selected production equipment.

\section{Description of the current system of mainte- nance of the selected production equipment}

\subsection{Description of the production equipment}

The primary research was focused on manufacturing equipment, where chemical technology production takes place and whose key elements are:

- Special coarse and fine mills.

- Air pipelines and fans.

- Continuous nitrators, centrifuges.

- Vibration filters.

- Absorption device used to regenerate acids.

- Supporting production equipment pumps, motors, special armatures, etc.

- Electrical installation, measuring and control equipment and control systems.

In the company, production equipment is divided according to its importance into three groups, which determines the method of planning repairs and other related activities. The researched production equipment belongs to the first group containing the main equipment. The capacity utilization rate of the production equipment in this group is at least 95 percent. In such operations, repairs and other related activities are planned mainly for the stop period. Unscheduled maintenance is a major problem because it directly threatens the firm's ability to meet customer requirements.

The analysis of repairs of production equipment showed a large number of repairs after failure. Vibration filters appear to be the most problematic as they had to be repaired 77 times in total in 2014. Another problem equipment is continuous nitrators, these four equipment required a total of 42 repairs after failure, most of which were done on the continuous nitrator number 1 (26 repairs after failure). Centrifuges are problematic devices as well. There are two devices in the manufacturing process; in 2014, 35 repairs after failure were required in total. The problematic nature of these devices is confirmed by the fact that it was the most defective device even in 2015. For the first half of the year, a total of 61 of repairs were made on all of these devices (continuous nitrators, centrifuges, vibrating filter) (Solilova 2015).

Therefore, it seems desirable to examine the possibilities of improving the maintenance system in this production process.

\subsection{Production equipment maintenance system}

Maintenance strategy for each device is based on the strategy of the entire enterprise. The basic objective is to guarantee operability of the production equipment while exerting optimum maintenance costs, all that being in accordance with the time needs of production and in order to meet customer requirements.

Maintenance of each production facility is scheduled by a rolling plan in a three-year horizon; the schedule is updated every year. A plan of maintenance and investment is made for each production process and production equipment. In turn, the maintenance schedule of the production equipment affects the budget for maintenance costs. The annual production equipment maintenance planning is greatly affected by years of experience of the mechanics.

Input data for annual maintenance planning are:

- National (or supranational) regulations.

- Internal guidelines, corporate manuals and instructions.

- Tutorials and recommendations from the producers. 
- Information obtained from the maintenance control process.

In the event that a production device requires a demanding maintenance (medium repair or overhaul), it is essential to plan this action in the enterprise-wide context.

The annual repair plan is supplemented by:

- A plan of revision inspections carried out for designated technical equipment (pressure, gas, electric, lifting).

- A lubrication program plan for each production device.

Maintenance operations are provided by own maintenance staff and external companies so that all required actions are performed in a timely manner. Tasks to be carried out by own maintenance crew are allocated among the individual maintenance department (mechanical, electrical, measurement/control). Scheduled maintenance of special production devices is provided either by the manufacturer of the device or a specialized company.

Repairs after failure are carried out by own maintenance department. If they cannot provide the capacity for a repair after the failure by our own staff, they are assisted by an external company.

As part of maintenance planning, a daily inspection of the condition and overall functionality is expected for all production equipment. The inspection is performed by operators.

Funds are allocated following the creation of a maintenance plan. An annual budget is prepared, being specific for each month. A monthly financial budget gives limits for preventive maintenance and repairs after failure.

Maintenance activities are implemented based on the plan. Given the importance of the production equipment, the scheduled repairs are carried out within the framework of an annual stop. The operation is usually stopped once a year for about 14 days. During this period, production is shut down; the equipment is completely cleaned and handed over to the maintenance to perform inspections, repairs or modifications of the equipment.

Outside the scheduled repairs, if necessary, repairs after failure are carried out.

After the maintenance, a check thereof is carried out. It includes:

- Reviewing the maintenance schedule on the merits.

- Check of quality of repairs.

- Assessment of repeated repairs.

- Assessment of stops.

- Assessment of the economy of maintenance.
In reviewing the maintenance schedule on the merits, the number of re-pairs made is monitored. This information is compared with the maintenance plan to identify deviations and take corrective measures.

Assessment of the quality of maintenance is performed by mechanics and service technicians who receive equipment from the service to the operation.

Repeated repairs after failure are assessed once a quarter. In the event of an increased presence of repair, medium or overhaul repairs are scheduled. In an extreme case, replacement of the equipment is considered.

Assessment of the stops is performed once a year, after stop is made. Its successfulness and efficiency is assessed.

To control the efficiency of maintenance, observed are:

- Implementation of planned events.

- Unfinished actions by month.

- Hours worked by the maintenance workers.

- Energy consumption in maintenance workshops (steam, electricity, water).

- Stocks in the maintenance storerooms.

- Use of total repair costs.

- Use of repair costs by type of costs.

- Accordance of the plan and the repair costs.

- Ratio of the costs of planned maintenance to the maintenance costs.

- Ratio of purchased maintenance to the maintenance costs.

Also, key performance indicators of maintenance are monitored in two groups. Expense-torevenue ratio indicators are monitored (the repair costs, the share of external maintenance, the ratio of the re-pair costs to the replacement value of the property and the ratio of the costs of planned maintenance to the maintenance costs) and productivity (the number of employees in maintenance, the use of the maintenance staff working time and the number of overtime hours of the maintenance workers) (Solilova 2015).

\section{Discussion}

The content analysis of information obtained by the primary research showed that the maintenance system applied has its imperfections as it is necessary to perform a relatively large number of repairs after failure on the examined manufacturing equipment. The need to make repairs after failure increases the risk of the company's inability to meet its commitments in relation to customers, but also the risk of excessive damage to the production 
equipment due to failure, the risk of lengthening the time needed for repairs (due to unpreparedness of spare parts, necessary technical documentation and maintenance staff), the risk of chaos as well as the need of highly skilled maintenance workers forced to react to unplanned situations. Reducing the number of repairs after the failure, however, requires a change in the examined maintenance system, especially:

- Improve work with information. In 2007, the enterprise implemented an information system to support maintenance. The information system helps the enterprise to collect data and keep records of maintenance of the production equipment. The information system should, however, contain a larger portfolio of information and, in addition to the number of repairs after failure, at least the causes and consequences thereof. This will allow the company to correctly set the maintenance strategy for the production equipment. The addition of information on all production equipment in the information system is a prerequisite to synchronization of the maintenance activities across the enterprise. The information system can also significantly improve synergies between the maintenance department and the purchasing department (providing spare parts for maintenance).

- Elaborate the maintenance system. The examined system can hardly be considered as prevention-based, namely with regard to the fact that the scheduled maintenance is only once a year within the stop of the production equipment. To improve the system, it seems desirable to set a shorter cycle of repairs, elaborate a technology for various kinds of repairs and determine a number of maintenance personnel required for preventing repairs after failure and, at the same time, for optimizing the time needed for maintenance. An analysis of time for repairs after failure could pose a time limit for applying preventative maintenance. Improvements in work with information could also give a basis for applying the RCM method in the manufacturing process, thereby contributing significantly to increase the reliability of the production equipment.

- Optimize the system of periodic preventive planned repairs by improving operations reducing physical degradation of the production equipment. Since the production equipment in the manufacturing process is under a constant influence of acids, there is an increased probability of frequent corrosion, which can be prevented using corrosion protection of the inner surface of the production equipment. The enterprise can apply suitable coatings, rubber coating or plating to the inner surface of the production equipment. At the same time, it is possible to reconsider the lubrication program, especially the lubrication interval, which can reduce the failure rate of vibration filters and centrifuges.

- Apply Condition-based maintenance (CBM) in order to reduce the number of repairs after failure, especially in vibration filters. This would allow the enterprise to continuously monitor the strength of the vibrations and perform the repair before reaching the limit of degradation of the production equipment.

- Perform a detailed analysis of repairs after failure, their number, their causes and consequences, which will not only allow a differentiated RCM-based approach to the maintenance of individual parts of the manufacturing equipment, but it will also provide the necessary information to make decisions about replacement investments.

- Secure human resources to perform the maintenance. A large part of the maintenance staff will retire in the near future and in terms of qualification requirements it is a significant challenge to replace them. In the highly specialized activities (e.g. work with winding in motors) any replacement is virtually impossible to find. In this case, the appropriate way to resolve the situation is either to outsource necessary maintenance activities or to develop cooperation with an appropriate educational institution associated with additional training within working stays.

- Improve the quality of work of the maintenance staff in the implementation of maintenance operations (mainly those of the preventive nature). This can be achieved while adhering to the scheduled maintenance time, by setting norms for the maintenance staff. Their remuneration should then reflect their respective performance.

- Finally, the maintenance of production equipment can be made more efficient through better management of spare parts. At present, the company has a relatively large supply of spare parts. This is mainly due to the fact that each manufacturing device needs different spare parts. The problem could be eliminated through the unification of spare parts for the devices. However, this would first require innovation in the production equipment (replac- 
ing old parts with new, more universally applicable parts). Another way of reducing the stock of spare parts is to enhance collaboration with suppliers supporting maintenance on the basis of the Quick Response method. This method of collaboration with suppliers would not only reduce the costs, but also increase the flexibility of suppliers.

\section{Conclusions}

Being consistent with theoretical approaches, the primary research confirmed that the creation and implementation of appropriate maintenance strategy requires a detailed analysis of input information. Only on this basis, we can devise individual strategy (and consequently the tactics and operations) in maintenance. They must be clearly individualized for each device and reflect its specifics (in particular wishes and requirements of customers, the competitive situation in the served markets and market segments, the nature of the manufactured products, the type of manufacturing process, the age of the production equipment and the possibilities of implementing technological innovations on it, etc.). The primary research showed that an optimum maintenance system, chosen as part of a maintenance strategy, need not be based on only one of the methods used, but several methods can be implemented simultaneously. The basis for successful maintenance of the production equipment is to identify which of the methods to deploy and how to combine these methods or their principles. A way to improve the corporate maintenance systems may also be to implement maintenance methods and systems, which were primarily designed for other industrial sectors and manufacturing equipment used therein, such as the Condition-based maintenance, CBM. This method can only be used with limited success in conventional production equipment in which there is chemicaltech production taking place, but it can very well be used in additional devices (such as vibration filters). The research showed that there can be a number of ways to improve maintenance of the production equipment, and in many cases they affect other functional areas of the company. Therefore, it seems desirable to engage a wider portfolio of the company employees in improving the maintenance of the production equipment.

\section{References}

Aghezzaf, E.; Khatab, A.; Tam, P. L. 2016. Optimizing production and imperfect preventive maintenance planning's integration in failure - prone manufac- turing systems, Reliability Engineering \& System Safety 145(January): 190-198.

http://dx.doi.org/10.1016/j.ress.2015.09.017

Al-Najjar, B.; Alsyouf, I. 2004. Enhancing a company's profitability and competitiveness using integrated vibration-based maintenance: a case study, European Journal of Operation Research 157(3): 643-657. http://dx.doi.org/10.1016/S0377-2217(03)00258-3

Al-Turki, U. 2011. A framework for strategic planning in maintenance, Journal of Quality in Maintenance Engineering 17(2): 150-162. http://dx.doi.org/10.1108/13552511111134583

Bakri, A. H.; Rahim, A. R. A.; Yusof, N. M.; Ahmad, R. 2012. Boosting lean production via TPM, in International Congress on Interdisciplinary Business and Social Sciences 2012 (ICIBSoS 2012), 1-2 December 2012, Jakarta, Indonesia.

Branska, L.; Silhava, K. 2010. Increasing of equipment reliability by RCM application, Scientific Papers of the University of Pardubice, Series A 16: 179-190.

British Standards Institution (BSI). 1984. BS 3811: glossary of maintenance terms in terotechnology. British Standard Institution, London.

Cervenka, Z. 2001. Maintenance management using computer - introduction to issues and benefits for users, Automa 7(7-8): 2-4.

Chan, F. T. S.; Prakash, A. 2012. Maintenance policy selection in manufacturing firms using the fuzzy MCDM approach, International Journal of Production Research 50(23): 7044-7056. http://dx.doi.org/10.1080/00207543.2011.653451

Chelbi, A.; Ait-Kadi, D. 1999. An optimal inspection strategy for randomly failing equipment, Reliability Engineering \& System Safety 63(2): 127-131. http://dx.doi.org/10.1016/S0951-8320(98)00031-3

Chompuinwai, R.; Tipgunta, S.; Sunawan, A. 2008. Implementation of total productive maintenance in healthcare: a pilot study, in 5th International Conference on Service Systems and Service Management, 30 June - 2 July 2008, Melbourne, Australia.

Dekker, R. 1996. Applications of maintenance optimization models: a review and analysis, Reliability Engineering and System Safety 51: 229-240. http://dx.doi.org/10.1016/0951-8320(95)00076-3

Duffuaa, S. O. 2000. Mathematical models in maintenance planning and scheduling. New York: Springer.

Hale, A. R.; Heming, B. H. J.; Smit, K.; Rodenburg, F. G. Th.; van Leeuwen, N. D. 1998. Evaluating safety in the management of maintenance activities in the chemical process industry, Safety Science 28(1): 21-44. http://dx.doi.org/10.1016/S0925-7535(97)00061-1

Hijes, F. C. G.; Cartagena, J. J. R. 2006. Maintenance strategy based on a multicriterion classification of equipments, Reliability Engineering \& System Safety 91(4): 444-451.

http://dx.doi.org/10.1016/j.ress.2005.03.001 
Jelinkova, M.; Munzarova, S. 2007. Modern conception of the value for a customer in CRM, in International Scientific Conference Customer Relationship Management '07 (CRM 2007), 10-11 September 2007, Lázně Bohdaneč, Czech Republic.

Khalaf, A.; Djouani, K.; Hamam, Y.; Alayli, Y. 2015. Maintenance strategies and failure - cost model for medical equipment, Quality and Reliability Engineering International 31(6): 935-947. http://dx.doi.org/10.1002/qre.1650

Lieckens, K. T.; Colen, P. J.; Lambrecht, M. R. 2015. Network and contract optimization for maintenance services with remanufacturing, Computers \& Operations Research 54(2): 232-244. http://dx.doi.org/10.1016/j.cor.2014.10.003

López-Santana, E.; Akhavan-Tabatabaei, R.; Dieulle, L.; Labadie, N.; Medaglia, A. L. 2016. On the combined maintenance and routing optimization problem, Reliability Engineering \& System Safety 145(1): 199-214.

http://dx.doi.org/10.1016/j.ress.2015.09.016

Lycke, L. 2003. Team development when implementing TPM, Total Quality Management \& Business Excellence 14(2): 205-213.

http://dx.doi.org/10.1080/1478336032000051395

Makovec, J. 1998. Organization and planning of production. Prague: VŠE.

Maletic, D.; Lovrencic, V.; Maletic, M.; Al-Najjar, B.; Gomiscek, B. 2015. Maintenance solutions for cost - effective production: a case study in a paper mill, in P. W. T. Tse, et al. (Eds.). Engineering Asset Management - Systems, Professional Practices and Certification. Hong Kong: Springer International Publishing. http://dx.doi.org/10.1007/978-3-319-09507-3 33

Marquez, A. C.; Gupta, J. N. D. 2006. Contemporary maintenance management: process, framework and supporting pillars, Omega 34(3): 313-326. http://dx.doi.org/10.1016/j.omega.2004.11.003

Martorell, S.; Munoz, A.; Serradell, V. 1996. Agedependent models for evaluating risks and costs of surveillance and maintenance of components, IEEE Transactions on Reliability 45(3): 433-442. http://dx.doi.org/10.1109/24.537014

Martorell, S.; Sánchez, A.; Serradell, V. 1999. Agedependent reliability model considering effects of maintenance and working conditions, Reliability Engineering \& System Safety 64(1): 19-31. http://dx.doi.org/10.1016/S0951-8320(98)00050-7

Muchiri, P. N.; Pintelon, L.; Martin, H.; Chemweno, P. 2014. Modelling maintenance effects on manufacturing equipment performance: results from simulation analysis, International Journal of Production Economics 52(11): 3287-3302.

http://dx.doi.org/10.1080/00207543.2013.870673
Murthy, D. N. P.; Atrens, A.; Eccleston, J. A. 2002. Strategic maintenance management, Journal of Quality in Maintenance Engineering 8(4): 287-305. http://dx.doi.org/10.1108/13552510210448504

Park, J. Y; Jang, S. 2014. Why do customers switch? More satiated or less satisfied, International Journal of Hospitality Management 37: 159-170. http://dx.doi.org/10.1016/j.ijhm.2013.11.007

Peters, R. W. 2001. Maintenance management and control, in G. Salvendy (Ed.). Handbook of Industrial Engineering: Technology and Operation Management. New York: John Wiley \& Sons, Inc. http://dx.doi.org/10.1002/9780470172339.ch59

Rustogi, K.; Strusevich, V. A. 2012. Single machine scheduling with general positional deterioration and rate - modifying maintenance, Omega 40(6): 791-804.

http://dx.doi.org/10.1016/j.omega.2011.12.007

Savsar, M. 2006. Effects of maintenance policies on the productivity of flexible manufacturing cells, Omega 34(3): 274-282.

http://dx.doi.org/10.1016/j.omega.2004.10.010

Solilova, T. 2015. Maintenance planning in a chemical industry: Master's thesis. University of Pardubice, Czech Republic.

Tan, Z.; Li, J.; Wu, Z.; Zheng, J.; He, W. 2011. An evaluation of maintenance strategy using risk based inspection, Safety Science 49(6): 852-860. http://dx.doi.org/10.1016/j.ssci.2011.01.015

Van Horenbeek, A.; Pintelon, L. 2014. Development of a maintenance performance measurement framework - using the analytic network process (ANP) for maintenance performance indicator selection, Omega 42(1): 33-46. http://dx.doi.org/10.1016/j.omega.2013.02.006

Vlckova, V. 2012. Kaizen as the tool for supply chain flexibility raising, in International Carpathian Logistics Congress (CLC 2012), 7-9 November 2012, Jesenik, Czech Republic.

Whitaker, L. R.; Samaniego, F. J. 1989. Estimating the reliability of systems subject to imperfect maintenance, Journal of the American Statistical Association 84(405): 301-309. http://dx.doi.org/10.1080/01621459.1989.10478770

Zhang, Z.; Wu, S.; Li, B.; Lee, S. 2013. Optimal maintenance policy for multicomponent systems under Markovian environment changes, Expert Systems with Applications 40(18): 7391-7399.

Ziegler, J. Maintenance of equipment. 1993. Ostrava: VŠB. http://dx.doi.org/10.1016/j.eswa.2013.07.003 